\title{
LA VOZ IMPROPIA: POESÍA Y POLÍTICA
}

\section{Ana Porrúa*}

\begin{abstract}
Resumen: Este trabajo se propone revisar algunos clivajes de la creación o la inscripción de las voces políticas en la poesía de América Latina a partir de procesos de apropiación y expropiación, asociada a la potencia de una figura anacrónica, el canto. En este sentido, estar adentro o afuera del canto, supone tanto la homogeneidad de ciertos tonos, el elegíaco, el imperativo, o el desalojo de los mismos, como la asunción de un punto de vista sonoro en relación con una idea de la temporalidad histórica que funcionaría como filtro, como tímpano que silencia las otras voces bajo el peso de las metáforas que hacen pie en la naturaleza, o como superficie perforada por donde la voz de los otros se filtra.
\end{abstract}

Palabras clave: Voz. Poesía. América Latina. Política. Canto.

Siempre sentí que la poesía tenía que ver con el sonido, y a la vez, en mi adolescencia (como retorno, por qué no de la infancia) el sonido de esa poesía tenía que ver con la propia voz, con el recitado de memoria. Según pasan los años y en contextos no muy académicos, aunque sí de enseñanza, ante la pregunta de qué diferencia a la poesía del resto de la literatura voy hacia una certeza que daría mucho trabajo explicar en términos teóricos y que prefiero tratar de desandar desde la experiencia de lectura: La poesía suena. No pienso siquiera en el tipo de verso, en las medidas, o en las rimas finales o internas, sino más bien en una voz que está allí diciendo algo y en uno o en muchos ritmos. La poesía, aún leída en silencio, suena, se escucha.

Por eso hoy me interesa revisar, o al menos presentar, algunas pocas escenas en que la voz se inscribe en la poesía, empezando por algún momento en que esta última se asocia al canto. "Canta oh Musa, la cólera del Pélida Aquiles", dice en el inicio La Ilíada y todos sabemos que la petición de la voz es una cláusula clásica y sin embargo allí ya hay algo del orden de la impropiedad de la voz propia, o de una voz de la poesía que estaría por fuera de la propia voz. Pero no iré hacia el principio de los tiempos, hacia las formas orales de la poesía, hacia la relación entre la poesía y la lira, o entre la poesía y la narración de los sucesos épicos, sino hacia algunos ejemplos en los que la poesía ya es eso que se lee, es decir, la poesía moderna. Y además, hacia otras geografías más cercanas, hacia América Latina, cuando por ejemplo, el venezolano Andrés Bello, hace su petición a la naturaleza en el inicio de "La agricultura de la zona tórrida" (1826): “iSalve, fecunda zona,/ que al sol enamorado circunscribes" (1979, p. 40), y esa solicitud permite abrir el despliegue del paisaje productivo desde el exilio londinense. Y entonces, más que una cláusula lo que aparece es un aditivo, el vocativo es un gesto solemne de pedido de la voz asociado a una voz que ya está en otro lado, anunciando los cafetales, las plantas de maíz y el añil que se extrae del nopal y que forma parte de un proceso industrioso bajo una mirada propia de la Ilustración. En qué se parece (no voy a responderlo ahora) ese "Salve,

\footnotetext{
* Doctora en Letras por la Universidad Nacional de Buenos Aires. Docente en la Universidad Nacional de Mar del Plata e Investigadora Independiente de CONICET. E-mail: porruana@gmail.com.
} 
fecunda zona" a la invitación de Neruda en Canto general: "Sube conmigo, amor americano.// Besa conmigo las piedras secretas./ La plata torrencial del Urubamba/ hace volar el polen a su copa amarilla." ("VIII", "II Alturas del Macchu Picchu" (1955, p. 30)). La naturaleza americana, aunque de distinto signo, tiene un lugar central en ambos poemas políticos; pero es el poeta ahora el que nos lleva.

II

Tierra mía sin nombre, sin América, estambre equinoccial, lanza de púrpura, tu aroma me trepó por las raices hasta la copa que bebia, hasta la más delgada palabra aún no nacida de mi boca. Pablo Neruda ${ }^{1}$

Yo no vengo a resolver nada.

Yo vine aqui para cantar

$y$ para que cantes conmigo.

Pablo Neruda ${ }^{2}$

La relación entre poesía y canto se mantiene asociada por siglos a la poesía de tintes épicos, a la poesía civil o a la poesía política. Vuelvo por un momento a una de mis primeras lecturas, a Pablo Neruda, para pensar justamente su inscripción como canto político y también cuál fue el efecto de esa voz que se ha vuelto, para mi, antigua, casi arcaica. En Canto general, el libro publicado en 1950, el aliento de la narración épica está presente, es el sonido de base: "Los carniceros desolaron las islas./ Guanahaní fue la primera/ en esta historia de martirios./ Los hijos de la arcilla vieron rota/ su sonrisa, golpeada/ su frágil estatura de venados,/ y aun en la muerte no entendían." ("Vienen por las islas (1493)", "III Los conquistadores" (NERUDA, 1955, p. 39)); suena una extraña narración en verso como una voz de la historia que por momentos se torna bíblica "Primero resistió la tierra.// La nieve araucana quemó/ como una hoguera de blancura / el paso de los invasores." ("XIX La tierra combatiente", "III Los conquistadores" (NERUDA, 1955, p. 64)).

Hay algo en el oído, sospecho que no sólo en el mio, que es conocido. Lo que suena de la historia de América latina contada/cantada por Neruda ha sonado en muchísimas ediciones posteriores a la de 1950, dispersas por muchísimos países; seguramente ha sonado en actos políticos, y, además, suena en gran parte de la canción política de los 60 y 70, en las letras de Quilapayun, de Carlos Puebla o de Los Jaivas, entre otros. ¿No escuchan ustedes a Los Jaivas cantando el Canto general? Una resonancia que una y otra

\footnotetext{
1 “Amor América (1400)", "I La lámpara en la tierra" (NERUDA, 1955, p. 3)

2 "VI", "IX Que despierte el leñador" (NERUDA, 1955, p. 363)
} 
vez retorna con una identidad que parece siempre exacta: ${ }^{3}$ "Como la copa de la arcilla era/ la raza mineral, el hombre/ hecho de piedras y de atmósfera, / limpio como los cántaros, sonoro." ("VI Los hombres", "I La lámpara en la tierra" (NERUDA, 1955, p. 17)). Más que aquello que dicen los poemas es el modo en que lo dicen el que educa un oído, una superposición interminable de metáforas asociadas a la tierra, al agua, a los elementos, que a veces, aniquilan el relato: ${ }^{4}$ suenan palabras, "raza", "mineral", "volcán de manos", "existencia territorial", "dioses vegetales", "útero verde" como epíteto de América; los hombres son de arcilla, de barro, que son, muchas veces, los calificativos de los "pueblos humillados". Todo enmarcado en las dos láminas que incluye la edición mexicana, una de Rivera, hecha de figuras prehispánicas; otra de Siqueiros, en la que un hombre sale, emerge de una especie de torbellino que no sabemos si es de arena o de agua, pero que arma una posible continuidad con el cielo. El aliento de la lengua es el mismo que el de los muralistas mexicanos, la materia es una materia común.

Territorial, continental, eso es lo general del canto nerudiano que se dice con el sonido de la poesía. El poeta invoca a América, luego pregunta, acicatea a los otros, pero también invoca el relato de los muertos, porque a Neruda lo que le interesa no es el paisaje "exportable" de Bello, claro y distinto, iluminado, sino la historia de un continente: "Mostradme vuestra sangre y vuestro surco,/ decidme: aquí fui castigado,/ porque la joya no brilló o la tierra/ no entregó a tiempo la piedra o el grano:/ señaladme la piedra en que caísteis/ y la madera en que os crucificaron,/ encendedme los viejos pedernales," ("XII", "II Alturas del Macchu Picchu" (NERUDA, 1955, p. 37)) y claramente trae una voz de los que ya no están: "Yo escuché una voz que venía/ desde el fondo estrecho del pique, / como de un útero infernal,/ y después asomar arriba/ una criatura sin rostro,/ una máscara polvorienta/ de sudor, de sangre y de polvo". Y si bien "Los hombres del nitrato" (ese es el título del poema), es decir los mineros, aparecen primero con una voz propia, remarcada por las comillas, "Mira,/ hermano, cómo vivimos,/ aquí en «Humberstone», aquí en «Mapocho»", lo que importa es la solemnidad del pedido final: "Y ése me dijo: "Adonde vayas,/ habla tú de estos tormentos,/ habla tú, hermano, de tu hermano/ que vive abajo,

\footnotetext{
${ }^{3}$ Los Jaivas es el nombre de una banda musical chilena que surge a principios de la década del 60. Su característica principal es la fusión, sobre todo en algunos de sus discos, entre el rock, el folklore y los ritmos latinoamericanos. En 1981 grabaron Alturas de Machu Picchu en el que musicalizan, justamente, poemas de la sección del Canto General de Neruda del mismo nombre.

${ }^{4}$ Transcribo como ejemplo un fragmento del poema "IV", de la sección "II Alturas del Macchu Picchu", de Canto general:

Cordillera esencial, techo marino.

Arquitectura de águilas perdidas.

Cuerda del cielo, abeja de la altura.

Nivel sangriento, estrella construida.

Burbuja mineral, luna de cuarzo.

Serpiente andina, frente de amaranto.

Cúpula del silencio, patria pura.

Novia del mar, árbol de catedrales.

Ramo de sal, cerezo de alas negras.

Dentadura nevada, trueno frío.

Luna arañada, piedra amenazante.

Cabellera del frío, acción del aire.

Volcán de manos, catarata oscura.

Ola de plata, dirección del tiempo (NERUDA, 1955, p. 34).
} 
en el infierno"." (V la arena traicionada, (NERUDA, 1955, pp. 250-251)). Y, por supuesto, el carácter fantasmagórico de esa voz oprimida, la de "una criatura sin rostro" que habla de su condición pero desde un útero, desde el fondo de la tierra. Finalmente esa voz, a la que le pide que sea su propia voz aparece como un resto insignificante y toma toda su dimensión cuando el poeta se convierte en portavoz, o más que en portavoz, en la voz de los otros: "Yo vengo a hablar por vuestra boca muerta.", y más adelante: "Apegadme los cuerpos como imanes./ Acudid a mis venas y a mi boca./ Hablad por mis palabras y mi sangre", para que la voz encarne, para que los cuerpos estén en el propio cuerpo (“XII", II Alturas del Macchu Picchu, (NERUDA, 1955, pp. 38-39)).

El canto es homogéneo, es solemne, tiene algo de ritual incluso, tramado, como ya dije, por cierta modulación bíblica o de cosmogonía americana, bajo el tono de la elegía pero también bajo la fuerza del imperativo. Y parte de una profundidad figurada, una especie de diseño lineal de la historia: el poeta canta el pasado de los pueblos indígenas de América, pero también de la revolución mexicana, de la figura de Sandino en Nicaragua, o de los dictadores de América Latina -Trujillo, Somoza, Carías-, o de la liberación de Stalingrado en la segunda guerra mundial; el poeta canta escandiendo los hitos de la historia porque es el que da a ver, el que construye ese friso o mural como testimonio y como llamado, tal como puede leerse en el poema final del libro, "Aquí termino (1949)", porque la voz del pasado tiene que pasar (justamente) por la del poeta ${ }^{5}$.

III

Como el que

$\sin \mathrm{voz}$

estudia

canto.

\footnotetext{
${ }^{5} \mathrm{Y}$ nacerá de nuevo esta palabra,

tal vez en otro tiempo sin dolores,

sin las impuras hebras que adhirieron

negras vegetaciones en mi canto,

y otra vez en la altura estará ardiendo

mi corazón quemante y estrellado.

Así termina este libro, aquí dejo

mi Canto general escrito

en la persecución, cantando bajo

las alas clandestinas de mi patria.

Hoy 5 de febrero, en este año

de 1949, en Chile, en "Godomar

de Chena", algunos meses antes

de los cuarenta y cinco años de mi edad.

(NERUDA, 1955, p. 532)
} 


\author{
Como el que \\ en el Canto \\ estudia \\ esa otra voz. \\ Como el que \\ sin voz \\ canta \\ en la voz \\ de esa otra voz. \\ Leónidas Lamborghini 6
}

¿Dónde están las voces, decía, y podríamos agregar, qué es el canto? Enrique Lihn, otro poeta chileno, publica en 1983 (treinta y tres años después del Canto general, y aún bajo la dictadura de Augusto Pinochet) El Paseo Ahumada y ahí sitúa las voces de los que hablan en el poema, en la calle, en ese pasaje de la ciudad de Santiago, un mercado urbano, popular, de mercancías. Los títulos de los poemas emulan lo que allí se escucha, la voz del mendigo por ejemplo, "SU LIMOSNA ES MI SUELDO. DIOS SE LO PAGUE", o titulares de diarios, carteles, "No por menos de $\$ 300$-dijo- y se enterró la daga en el costado. ESTUDIÓ MAGIA ROJA EN EL ECUADOR”; la voz aparece, sobre todo, como reproducción de estos titulares que desde el aspecto gráfico y como incrustación de collage en medio de los poemas funciona como tono saliente, destacado, casi como grito. Pero también como escritura de una pura oralidad, del canto publicitario y suplicante de los personajes del paseo: "Ni brujo ni carnicero mago con diploma que harrecorrido a pietodel cóontineente/ y ebstadáaga que'e mihundoenlscostado/ súaiudapogfavog" ("No por menos de \$300...” (LIHN, 1986)).

¿Será este el único canto posible de la poesía? El de Neruda tiene su lugar en El Paseo Ahumada, de hecho, como denegación: "Nuestro modelo inaccesible cantó desde lo alto de la montaña sagrada nosotros buscando al ras de suelo según/ nuestra adhesiva manera de dejarnos caer como escupitajo de plástico" ("Canto General” (LIHN, 1986)). Un abajo y un arriba que arman una cartografía sonora, una ubicación de la voz. Para Lihn, claramente, las voces del Canto general de Neruda (esas que lo eran sólo en tanto pasaban por la poesía) están separadas por una cualidad sagrada. Otra vez la montaña, pienso, otra vez -como en "La agricultura de la zona tórrida" de Bello-, la visión panorámica, un "punto de vista sonoro", un lugar desde el que se construye una voz política, aquél que supuestamente, dice Quignard, no existe sino en el orden de lo visible: "Lo que es oído no conoce párpados ni tabiques ni tapicerías ni murallas. Indelimitable, nadie puede protegerse de él. No hay un punto de vista sonoro. No hay terraza, ventana, torreón, ciudadela, mirador panorámico para el sonido. No hay sujeto ni objeto de la audición. El sonido se precipita. Es el violador" (QUIGNARD, 1996, p. 60).

\footnotetext{
6 "El cantor", Circus (LAMBORGHINI, 1986, p. 13)
} 
Tal vez la altura, aquella mencionada, de hecho, en el ascenso a las "Alturas de Macchu Picchu", uno de los títulos de sección del libro de Neruda, pueda pensarse bajo la figura de una audición total, aunque paradójicamente suponga la sordera ante aquellas voces de la historia política, o su transformación en la voz indistinta y distinguible de la poesía, del poeta, en canto, una voz propia que es a la vez expropiada. El canto, de hecho, se sustituye en El Paseo Ahumada por la escritura, y en la separación entre uno y otra, el poema pierde o desaloja el tono providencial, profético:

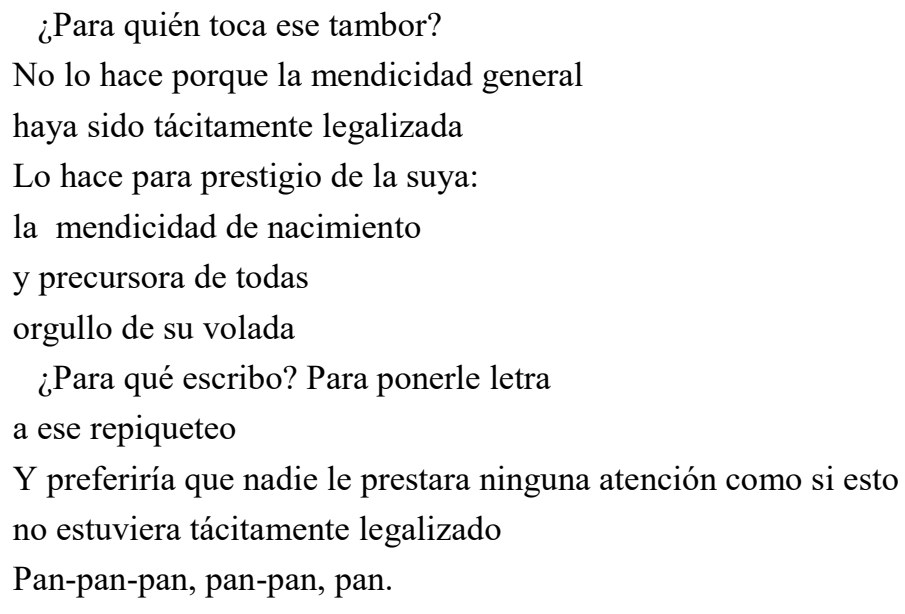

No perteneces al Ejército de Salvación, que te hace la feroz competencia

No pertenezco al Ejército de Liberación, que no existe

Repiqueteas por tu salvación personal

y yo escribo porque sí

Tocamos el tambor a cuatro manos

(“Tocamos el tambor a cuatro manos" (LIHN, 1986))

En todo caso, en el poema de Lihn, hay varios cantos, o cantos minúsculos (en minúscula) como el del que presenta sus haceres. Lo que se escucha, en realidad, ese repiqueteo, pasa a la letra; y sin embargo, la escritura se equipara, en términos éticos, políticos, con ese sonido de salvación personal, como un sonido retraído. La pérdida del canto es, sobre todo, la desaparición del tono utópico de las voces y de la propia voz. En cambio, en Canto general de Neruda, la voz de los otros, de los oprimidos de la historia, parece estar en el Canto con mayúscula, un sonido que antecede o cubre esas otras voces ("Como el que/ en el Canto/ estudia/ esa otra voz", dice el poema de Lamborghini citado en el epígrafe).

No hay voz propia, o en todo caso la poesía funciona como el tímpano o mejor, como el párpado del oído. Porque Neruda tapiza el oído, crea pasadizos metafóricos, una lengua que por momentos se levanta como muralla frente a la voz de los otros. Como si pensar en la poesía fuese lo contrario de pensar en unas voces que están afuera de la poesía, afuera de esa lengua, afuera de ese idioma; o como si la voz de esos otros tuviese que pasar por el tímpano recubierto de metáforas de Neruda para convertirse en verdaderamente histórica, para poder ser escuchada con ese filtro previo. Lihn, en cambio, sitúa esas voces, como dije, en medio de la calle, y se define, en El Paseo Ahumada como 
"un minusválido de la canción", como un "cantante afásico". El Canto ya no es un filtro, un modo de amurallar o recubrir un oído. Ahora sí el sonido está más cerca de la caracterización de Pascal Quignard:

\begin{abstract}
Todo sonido es lo invisible bajo forma de perforador de coberturas. Ya se trate de cuerpos, de recámaras, de departamentos, de castillos, de ciudades amuralladas. Inmaterial, franquea todas las barreras. El sonido ignora la piel, no sabe lo que es un límite: no es interno ni externo. Ilimitante, no es localizable. No puede ser tocado: es lo inasible. La audición no es como la visión. Lo contemplado puede ser abolido por los párpados, puede ser detenido por el tabique o la tapicería, puede ser vuelto inaccesible incontinenti por la muralla (QUIGNARD, 1996, p. 60).
\end{abstract}

No digo que el sonido, en el poema de Lihn, franquee todas las barreras pero al menos sí algunas; sin embargo se localiza y se torna material, como el pan-pan del tambor. Tal vez, la voz política de El Paseo Ahumada tome cuerpo en este movimiento complejo de ruptura de las barreras y simultáneamente, de localización como materia.

Voy ahora hacia otro de los poemas políticos centrales en mi educación sentimental, sensible y, por qué no, auditiva. Me refiero a El Solicitante Descolocado de Leónidas Lamborghini que como libro se publica por primera vez en 1971 (mientras escuchábamos a Carlos Puebla, por ejemplo) pero que se inicia en 1955 con El Saboteador Arrepentido en una serie que se escande, entre otros libros, con Las patas en las fuentes, de 1965. Se trata de una saga histórica, que en este último título se dibuja alrededor del peronismo, ya que hace alusión a la conocida escena de la marcha del 17 de octubre de 1945, que se ha transformado en sinécdoque de identidad política, cuando Perón estaba preso, y los que llegan desde el gran Buenos Aires o desde los barrios, eligen remojarse los pies en la fuente de Plaza de Mayo, para aliviar el tiempo de caminata. Del recorrido cósmico americano de Canto general de Neruda al situado de El Paseo Ahumada, o esta serie de Lamborghini, algo cambió de manera visible. Y sin embargo, no diría, no quiero decir que a una modalidad de la voz le sigue otra, trazar una cronología de la voz en este sentido, sino más bien, dejar planteado lo que para mi es una marca indeleble, el anacronismo de esta voz política que convive aun hoy cuando las metáforas nerudianas, que antes fueron las metáforas de las vanguardias del 20, y luego estuvieron en la canción política, siguen sonando en la marcha política, en la oratoria latinoamericanista cuando Hugo Chávez viaja a Argentina por la muerte de Néstor Kirchner y dice "Yo no vine aquí a sepultar a Néstor, a Néstor lo vamos a sembrar", o incluso en algunas canciones de Calle 13, como "Latinoamérica".

Hay varias figuraciones del canto en El Solicitante Descolocado, pero abro con una que nos sitúa rápidamente en el cambio de tono, cuando el Saboteador y el Solicitante cierran conjuntamente la primera parte: "1, 2, 3/ No canto más/ -Explotando-/ Do re mi fa sol la/ ¡Sí!/ Poniendo en marcha la/ Fábrica” (LAMBORGHINI, 1971, p. 24). Más cerca del circo que del canto ceremonial; más cerca del presente que de un pasado muerto. El libro, más allá de las voces de los personajes, por llamarlos de algún modo, que remedan la dramática de la gauchesca argentina, está plagado de segmentos de las voces de la política, la mayor parte del tiempo encomillados. Así aparecen las voces de la Resistencia Peronista a partir de los sobrevivientes de la masacre de José León Suárez (1956), que Lamborghini reescribe desde los testimonios publicados por Rodolfo Walsh 
en Operación masacre, pero también un remedo de la voz de "los libertadores", los representantes de la dictadura llamada Revolución Libertadora. Y hay una escena, en la que se escuchan consignas en la plaza: "La insurrección es un arte", "aquí los únicos privilegiados/ son los privilegiados", "La decisión es un don/ de la inteligencia", "y el coraje/ (...)/ es su acción”, "y también/ cuando metimos las patas el poder/ en las fuentes de la Gran Plaza" (LAMBORGHINI, 1971, pp. 75-77); estas se unen además a otras consignas o frases que emergen intermitentemente en todo el libro: "La tierra para el que la trabaja" (1971, p. 11), "La vida por/ la vida por" (1971, p. 37) con ese corte que se sabe, es el del nombre del Líder; y también frases del sentido común, como "me jodió/ la política", "Oh oh en aquella época/ yo compré/ una vaquita/ por un peso" (1971, p. 30). El primer efecto es obvio pero no por eso menos saliente, el poema está perforado; la voz del poeta que cantaba por los que no tienen voz, llena de tonos, gritos altisonantes, risas. A la vez, si Neruda debía escuchar aquello que sonaba en las profundidades de América (en su útero), Leónidas Lamborghini abre una escena dramática en la que los tiempos se superponen, porque el pasado, los distintos pasados emergen en el presente. Las voces en el presente y como conflicto. No hay una voz unitaria, ¿quién dice "La tierra para el que la trabaja"? Y ¿quién la cantinela de que todo tiempo pasado fue mejor? ¿Quién dice La vida por Perón? ¿Es el mismo sujeto que dice que "La insurrección es un arte"? No importa la linealidad de la historia sino su serpenteo constante, no importa la interpretación única sino la multiplicidad de voces que incluso se contradicen. Incluso, desde esta superficie agujereada de sonidos, se podrían retomar unos versos del inicio del libro, cuando El Solicitante Descolocado hace su solicitud, "vena mía poética susúrrame" y la respuesta es "tú no tienes voz propia/ ni virtud" (LAMBORGHINI, 1971, p. 9). Porque lo que no hay, justamente, es una voz poética amparada en una tradición y, aún así, cerrada sobre sí misma sino la búsqueda de una voz heterogénea. La propiedad, en este caso, es la desapropiación del yo poético hablando en el círculo seguro del poema y la reapropiación de lo que suena por afuera de ese círculo.

Mladen Dolar dice que uno de los momentos en el que el logos de la voz se pierde (se separa prácticamente de la phoné) es el canto, y da el ejemplo de la ópera (DOLAR, 2007, p. 42-43). La voz de la política en la poesía de Neruda podría ser entendida en este sentido como puro canto, como el llamamiento de la historia de América Latina, como si esa historia fuese el Canto -con mayúsculas- sobre el que se educará el canto del poeta; la de los poemas de Lamborghini, en cambio, debería ser entendida más bien como una opereta, un canto de segunda jerarquía, en el que el espacio entre logos y phoné, esa instancia intermedia, de solapamiento entre una y otra, encuentra su lugar y se arma una pequeña caja de resonancia para que los decires públicos reboten unos contra otros, se escuchen unos a otros, se digan -incluso- unos a otros. Contra el canto, podría decirse, el ruido, el murmullo, el balbuceo. Y digo que se arma ese espacio intermedio porque $E l$ Solicitante Descolocado no es un libro documental, no es una toma directa de las voces sino que propone un artificio de las mismas, las escucha (las lee) y las reescribe en la más pura ambigüedad, sin profundidades a desentrañar, en el espacio público de la calle, de la plaza e incluso de la fábrica, por eso el tono elegíaco está minado por la ironía, al igual que el tono dramático. 
BELLO, Andrés. "La agricultura de la zona tórrida". In Obra literaria. Caracas: Biblioteca Ayacucho, 1979.

DOLAR, Mladen. Una voz y nada más. Traducción de Daniela Gutierrez y Beatriz Vignoli. Buenos Aires: Manantial, 2007 [2006].

LAMBORGHINI, Leónidas. El Solicitante Descolocado. Buenos Aires: Ediciones de la Flor, 1971. LAMBORGHINI, Leónidas. Circus. Buenos Aires: Libros de Tierra Firme, 1986.

LIHN, Enrique. El Paseo Ahumada. Santiago de Chile: Ediciones Minga, 1983. Disponible en http://www.memoriachilena.cl/archivos2/pdfs/MC0009670.pdf. Último ingreso 03/11/2016.

NERUDA, Pablo. Canto general. Buenos Aires: Losada, 1955. Disponible en http://www.cervantesvirtual.com/

QUIGNARD, Pascal. "Segundo tratado. Ocurre que las orejas no tienen párpados". In El odio a la música. Diez pequeños tratados. Traducción de Pierre Jacomet. Santiago de Chile: Editorial Andrés Bello, 1996, pp. 59-75.

Recebido em 13/10/2016. Aprovado em 12/11/2016

Title: The improper voice: poetry and politics

Abstract: This article intends to explore some cleavages of creation, or the inscription of political voices in Latin American poetry, departing from processes of appropriation and expropriation, associated with the potentialities of an anachronistic figure, singing. In this sense, being inside or outside singing presupposes both the homogeneity of certain tones the elegiac, the imperative - or their disowning, and the assumption of a sonorous point of view in relation to the idea of a historical temporality. This would function as a filter, as an eardrum that silences the other voices under the weight of metaphors sustained in nature, or as a perforated surface filtering through the voice of the others.

Keywords: Voice. Poetry. Latin America. Politics. Singing.

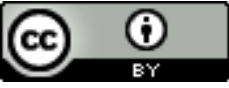

Este texto está licenciado com uma Licença Creative Commons Atribuição 4.0 Internacional. 